\title{
Bilateral Achilles Tendon Xanthoma in an 18-Year-Old Patient
}

\author{
S. K. Venkatesh Gupta, B. Sahithya, S. P. Prashanth \\ Department of Orthopaedics, Mamata Medical College, Khammam, Telangana, India \\ Email: sahithya.bandi008@gmail.com
}

How to cite this paper: Gupta, S.K.V., Sahithya, B. and Prashanth, S.P. (2017) Bilateral Achilles Tendon Xanthoma in an 18-Year-Old Patient. Open Journal of Orthopedics, 7, 110-116. https://doi.org/10.4236/ojo.2017.74013

Received: February 15, 2017

Accepted: April 27, 2017

Published: April 30, 2017

Copyright () 2017 by authors and Scientific Research Publishing Inc. This work is licensed under the Creative Commons Attribution International License (CC BY 4.0).

http://creativecommons.org/licenses/by/4.0/ (c) (7) Open Access

\begin{abstract}
Background: Xanthomas are rare, non-neoplastic lesions which occur due to defect in the LDL receptors leading to their accumulation in tendons and synovium. The prevalence of heterozygous familial hypercholesterolaemia (HFH) is approximately 1 in 500. Aim: To study a rare case of bilateral achilles tendon xanthoma and its functional outcome. Case Presentation: We presented a case of xanthoma over posterior aspect of both lower third legs just above the heel in an 18-year-old female, and diagnosis was confirmed by clinical examination ultrasound and MRI, for which subtotal resection was planned and further followed up. Postoperative treatment consisted of six weeks long leg cast immobilization. After 10 weeks the patient started walking without any difficulties. Conclusion: Subtotal resection of achilles tendon xanthoma has given a good functional outcome. There is no need for reconstruction of tendon in every case.
\end{abstract}

\section{Keywords}

Achilles Tendon Xanthoma, Low Density Lipoprotein, Magnetic Resonance Imaging, Ultrasound

\section{Introduction}

Xanthomas are non-neoplastic lesions and they are relatively common on the skin, especially on the eyelids [1]. The lesions are most frequently seen on tendons and synovium and they usually involve the extensor tendons of the hands, achilles tendons and patellar ligaments [1] [2]. Less commonly the lesion may affect the triceps and extensor tendon of toes. A strong tendency to recurrence was observed in surgically removed Achilles tendon lesions. Cerebrotendinousxanthomatosis (CTX) is an autosomal recessive, lipid storage disorder characterized by accumulation of cholestanol and cholesterol in the brain, spinal cord, peripheral nerves, tendons, lungs, liver and kidneys. Infantile onset diar- 
rhea, childhood onset cataract, progressive neurologic dysfunction are the most prominent features of this disease. The Achilles tendon xanthoma is a rare disease [3] and is highly associated with the familial hyperlipidemia [4]. Achilles tendon xanthoma is caused by a defect of the low-density lipoprotein (LDL) receptor [5] [6]. The low-density lipoprotein (LDL) derived from the circulation accumulates into the tendons leading to the formation of Achilles tendon xanthomas which are the transformation of LDL into oxidized LDL (oxLDL) and the active uptake of oxLDL by macrophages with in the tendons. They typically occur at the third decade of life with a female to male ratio as 4:3 [2]. Histologically these are composed of multinucleated giant cells, histiocytes (foamy macrophage), hemosiderin deposits. Large swelling of the tendocalcaneus results in weakness of plantar flexion and difficulty in walking hence surgery is carried out for these lesions. We present a case of xanthoma over posterior aspect of both lower third legs just above the heel in an 18-year-old female.

\section{Case Report}

An 18-year old female patient presented with complaints of swelling over posterior aspect of both lower third legs just above the heel since 15 years and pain over the swellings since 10 days. The swelling was insidious in onset, initially it was of peanut size and gradually progressed to about $8 \times 4 \times 2 \mathrm{~cm}$ at the time of presentation. Pain over the swelling was insidious in onset, dull aching type of pain, aggravating on walking and releaved on taking rest. History of similar type of swellings present over both the elbows and anterior aspect of both knees, except one lesion all others were excised 5 years back. Patient did not give any history of trauma or prick injury. There was no history of any kind of immobilization or massage treatment. At the age of 5 she was diagnosed with bilateral cataract and underwent PCIOL (posterior chamber intra-ocular lens) implantation. She is a known hypothyroid since 4 years old and on regular medication.

On examination, swelling extended from the lower third of both legs to just above the heel. It was globular in shape, skin over the swelling is smooth, surroundings skin is normal, there is no local rise of temperature, and swelling is firm in consistency, non tender, non reducible and non translucent, skin over the swelling is pinchable. It is fixed in horizontal direction, but swelling is mobile with the movement of her ankle joints which confirms that swelling is arising from tendo-achilles. All movements at ankle were normal and pain free. There was no muscle wasting and sensations were intact without any distal neurovascular deficits (Figure 1).

\section{Evaluation and Approach to Management}

Laboratory investigations like complete blood examination, complete urine examination, lipid profile and thyroid profile are with in normal limits.

Radiological examination:

X-ray revealed no bony involvement, but shows soft tissue shadow over both lower third legs just above the heel (Figure 2). 


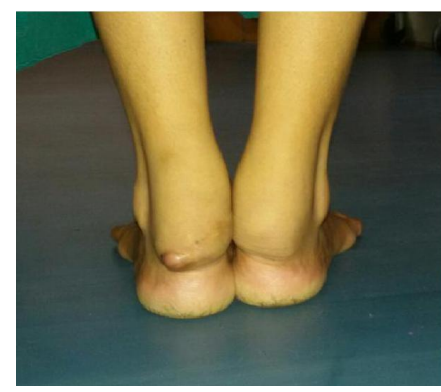

(a)

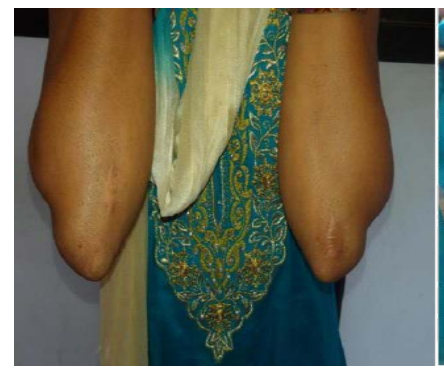

(c)

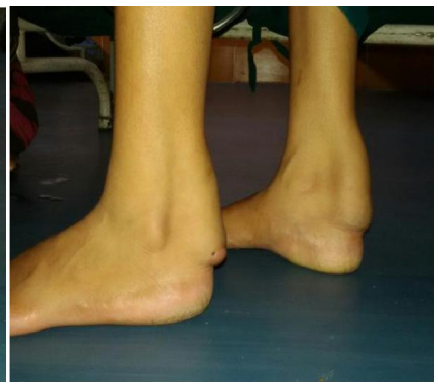

(b)

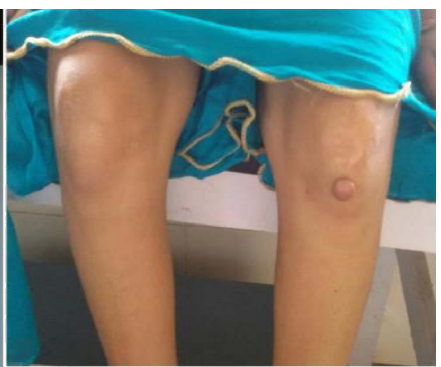

(d)

Figure 1. ((a), (b)): Clinical picture of swellings over posterior aspect of lower third both legs just above the heel; (c): Clinical picture showing old healed scars of similar swellings excised over both elbows; (d): Clinical picture showing swelling over anterior aspect of left knee.

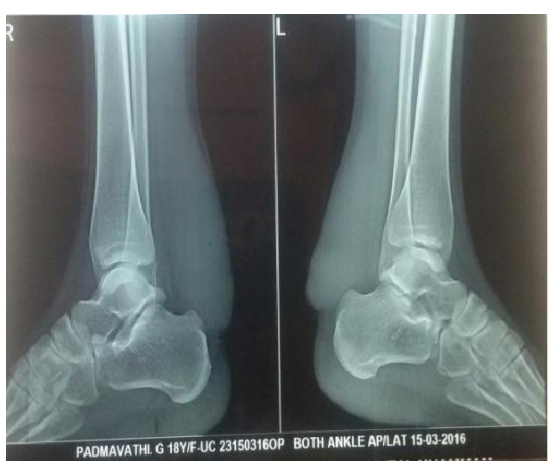

(a)

(b)

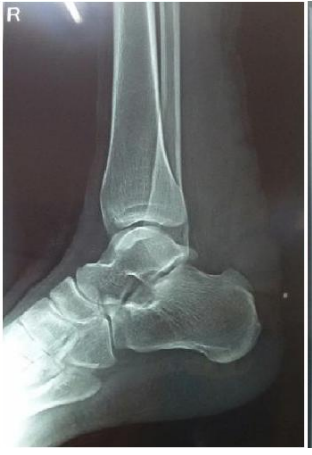

(c)

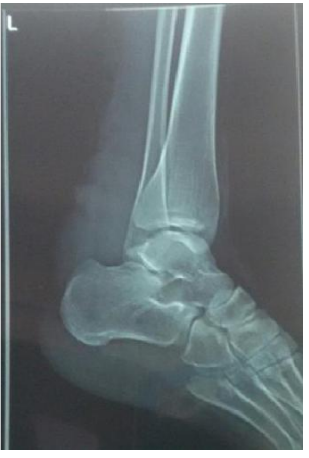

(d)

Figure 2. ((a), (b)): Pre-operative lateral radiographs of right and left legs with ankle showing bilateral soft tissue masses; ((c), (d)): Post-operative lateral radiographs of right and left legs with ankle.

MRI both ankles shows diffuse thickening of the achilles tendon with hypo-intensity on T1 \& T2 weighted images and heterogeneously hyper-intensity on PD and STIR images, extending from musculotendinous junction to the insertion at the calcaneum (Figure 3).

An ultra-sonographic scan showed a diffuse thickening of Achilles tendon with hypoechoic areas and other small hyperechoic confluences (Figure 4).

Histopathological detailing was done with fine needle aspiration cytology (FNAC) which reported features suggestive of xanthoma of tendon sheath.

Microscopic examination shows cellular smears comprising of multinucleated giant cells, mononuclear cells along with connective tissue fragments, few inflammatory cells and cyst macrophages with no evidence of malignancy (Figure 5). 
Gross examination of the specimen revealed large yellow-tanned soft-tissue mass that infiltrated the achilles tendons and adjacent tissues (Figure 6).

Biopsy findings confirmed the diagnosis of xanthoma of tendon sheath.

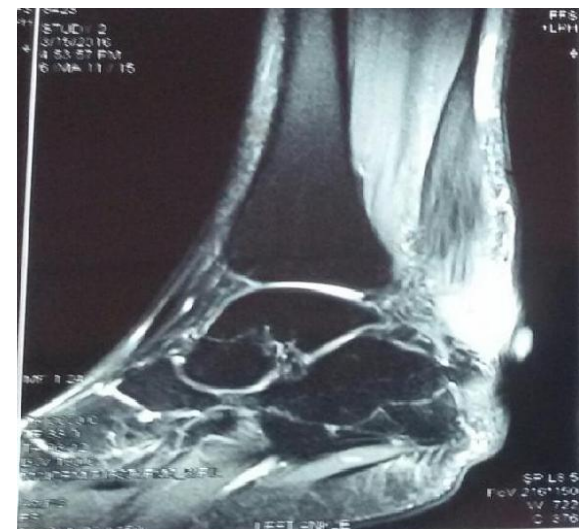

(a)

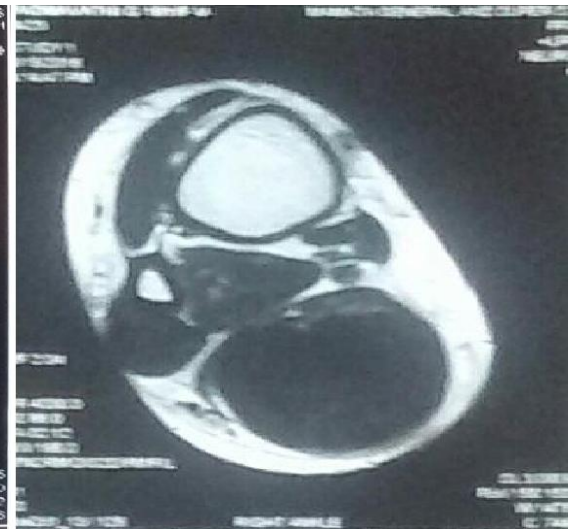

(b)

Figure 3. Saggital and axial sections on MRI shows a diffuse thickening of tendons with intermediate signal areas.

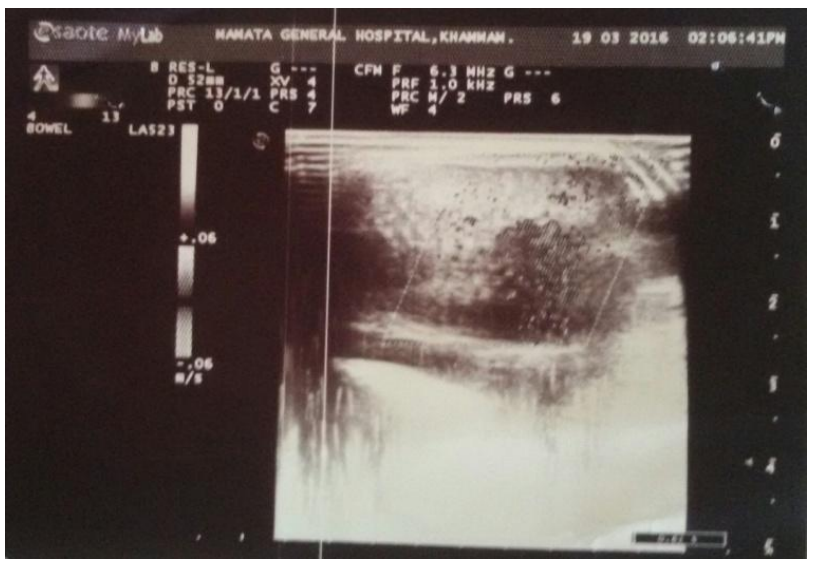

Figure 4. Ultrasound image shows a diffuse thickening of the achilles tendons with hypoechoic and small hyperechoic areas.

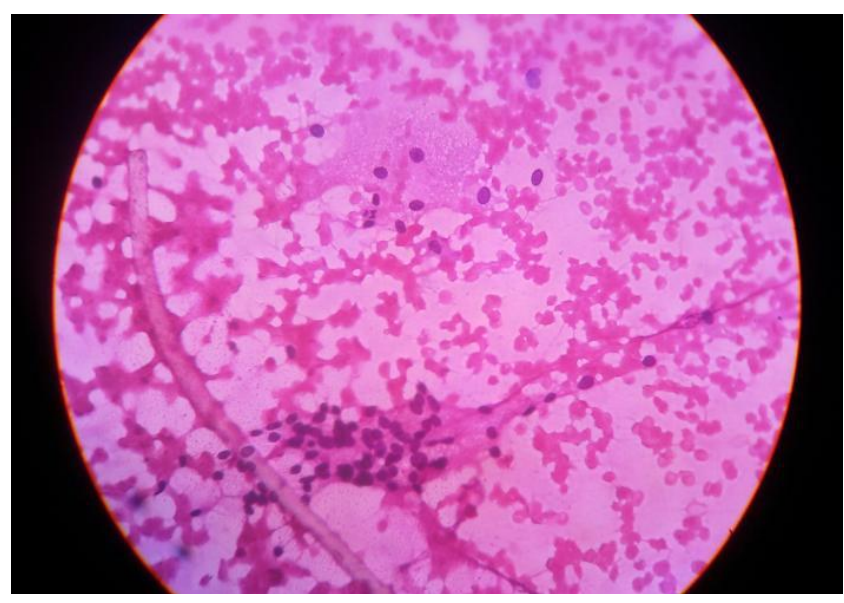

Figure 5. Histopathological picture showing histiocyte and multinucleated giant cell on haemorragic back ground. 


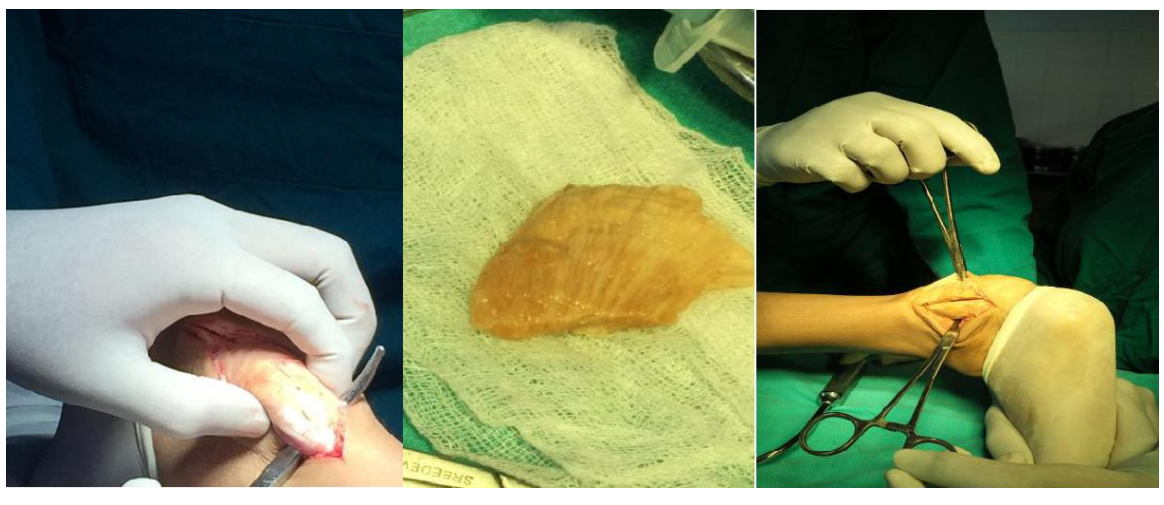

(a)

(b)

(c)

Figure 6. Intra operative pictures showing mass and gross morphology of excised tissue.

Postoperatively, ankle is immobilized in non-weight bearing lower leg cast at $10^{\circ}-15^{\circ}$ of plantar flexion for about 6 weeks. Suture removal was done on $15^{\text {th }}$ postop day and showed no evidence of wound dehiscence or discharge. At 8 weeks active ankle movements were started. After 10 weeks the patient started walking with walker without any difficulties.

\section{Discussion}

The Achilles tendon xanthoma is a rare condition [3], the number of lesions, cholesterol levels, age, and gender are correlated [7]. Tendon xanthomas presents as painless soft tissue masses occurring most commonly at the distal onethird of the Achilles tendon, usually bilaterally and symmetrically, and has a high association with primary familial hypercholesterolemia, an autosomal dominant inheritance and is characterized by an elevated LDL-cholesterol [8] [9], tendon xanthomas, and coronary artery disease [10].

Junyent et al. compared Achilles tendon sonography in patients with $\mathrm{FH}$ and in patients with non-FH dyslipidemias.

It appeared that sonographicxanthomas were only found in patients with $\mathrm{FH}$ [11].

Fahey et al. showed that a majority of patients with Achilles tendon xanthomas had a family history of coronary disease. In the present case the lipid profile was normal and there is no family history of coronary artery disease [2].

It is characterized by a local concentration of multinucleated giant cells, lipid-laden foamy macrophages, and other inflammatory cells in response to cholesterol deposition in tissues. They are relatively common, with most of them occurring on the skin, and most frequently seen on tendons and synovium and they usually involve the extensor tendons of the hands, achilles tendons, and patellar ligaments [1]. They typically occur at the third decade with a female to male ratio as 4:3 [2]. Bilateral Achilles tendon involvement was seen in $90 \%$ of cases.

It is characterized by a local concentration of multinucleated giant cells, lipid-laden foamy macrophages, and other inflammatory cells in response to cholesterol deposition in tissues. They are relatively common, with most of them 
occurring on the skin, and most frequently seen on tendons and synovium and they Clinical manifestations of Achilles tendon xanthomas depend on the lesion sizes. The smaller lesions are often asymptomatic. The larger lesions are clinically apparent and manifest as cosmetically disfiguring masses which can impair ambulation and cause local pain [4].

The different subtypes of xanthomas are xanthomadisseminatum, verruciformxanthoma, cutaneous xanthomas are subdivided into xanthelasmapalpebrum, tuberous xanthoma, tendinousxanthoma, eruptive xanthoma, generalized plane xanthoma, cauliflower xanthoma, palmar xanthoma and plantar xanthoma.

Imaging studies are usefull tools in diagnosing xanthoma. On X-rays tendon xanthomas are shown either as an abnormal tendon thickening or soft tissue noncalcified masses with a nonspecific appearance. The ultrasound and MRI were more helpful and specific to characterize this condition.

Surgical treatment of achilles tendon xanthomas is rare and is usually limited to those patients who have severe disfigurement, pain or problems with mobility caused by the mass. It includes either 1) Complete excision and reconstruction of the defect with fascial grafts or 2) Subtotal/Partial excision. To preserve the function of the achilles tendon and for less complications the lesions are often partially removed. In the present case we have chosen subtotal excision of xanthoma, where we have removed the central mass and left the superior and inferior flaps sutured in situ, so no reconstruction was done.

\section{Conclusion}

Xanthomas are benign conditions. In our case, it presented as enlarged mass over posterior aspect of both lower third legs just above the heel (Figure 1). After clinical diagnosis, we proceeded with ultrasonography and MRI [5] and finally FNAC was done. Microscopic examination revealed multinucleated giant cells and histiocytes (Figure 5) after correlating the clinical history and presentation with the pathological findings, and a diagnosis of xanthoma of achilles tendon was concluded. And we recommend for bilateral subtotal excision of xanthomas, and later above knee plaster slab applied with foot in neutral attitude. Later patient was followed up every 4 weeks for further recurrence, till date she had no compliations and partial weight bearing started with the help of walker after $8-12$ weeks. There was about $50 \%$ recurrence seen in a partially resected xanthoma of Achilles tendon.

\section{Acknowledgements}

The study includes no funding.

\section{References}

[1] Fair, K.P. (2008) Xanthomas. Emedicine. http://www.emedicine.com/derm/topic461.htm

[2] Fahey, J.J., Stark, H.H., Donovan, W.F. and Drennan, D.B. (1973) Xanthoma of the 
Achilles Tendon: Seven Cases with Familial Hyperbetalipoproteinemia. The Journal of Bone \& Joint Surgery, 55, 1197-1211. https://doi.org/10.2106/00004623-197355060-00007

[3] Carranza-Bencano, A., Fernandez-Centeno, M., Leal-Cerro, A., Duque-Jimeno, V., Gomez-Arroyo, J.A. and Zurita-Gutierrez, M. (1999) Xanthomas of the Achilles Tendon: Report of a Bilateral Case and Review of the Literature. Foot \& Ankle International, 20, 314-316. https://doi.org/10.1177/107110079902000509

[4] Mabuchi, H., Ito, S., Haba, T., Ueda, K., Ueda, R., et al. (1977) Discrimination of Familial Hypercholesterolemia and Secondary Hypercholesterolemia by Achilles' Tendon Thickness. Atherosclerosis, 28, 61-67. https://doi.org/10.1016/0021-9150(77)90199-X

[5] Yamakawa, K., Yanagi, H., Saku, K., Sasaki, J., Okafuji, T., Shimakura, Y., et al. (1991) Family Studies of the LDL Receptor Gene of Relatively Severe Hereditary Hypercholesterolemia Associated with Achilles Tendon Xanthomas. Human Genetics, 86, 445-449. https://doi.org/10.1007/BF00194631

[6] Descamps, O.S., Leysen, X., Van Leuven, F. and Heller, F.R. (2001) The Use of Achilles Tendon Ultrasonography for the Diagnosis of Familial Hypercholesterolemia. Atherosclerosis, 157, 514-518. https://doi.org/10.1016/S0021-9150(01)00533-0

[7] Murano, S., Shinomiya, M., Shirai, K., Saito, Y. and Yoshida, S. (1993) Characteristic Features of Long-Living Patients with Familial Hypercholesterolemia in Japan. Journal of the American Geriatrics Society, 41, 253-257. https://doi.org/10.1111/j.1532-5415.1993.tb06702.x

[8] Goldstein, J.L., Hobbs, H. and Brown, M.S. (1995) Familial Hypercholesterolemia. In: Scriver, C.R., Beaudet, A.L., Sly, W.S. and Valle, D., Eds., The Metabolic \& Molecular Bases of Inherited Disease, 7th Edition, McGraw-Hill, New York, 1981-2030.

[9] Austin, M.A., Hutter, C.M., Zimmern, R.L. and Humphries, S.E. (2004) Genetic Causes of Monogenic Heterozygous Familial Hypercholesterolemia: A HuGE Prevalence Review. American Journal of Epidemiology, 160, 407-420. https://doi.org/10.1093/aje/kwh236

[10] Liem, M.S., Gevers Leuven, J.A., Bloem, J.L. and Schipper, J. (1992) Magnetic Resonance Imaging of Achilles Tendon Xanthomas in Familial hypercholesterolemia. Skeletal Radiology, 21, 453-457.

[11] Junyent, M., Gilabert, R., Zambón, D., Núñez, I., Vela, M., et al. (2005) The Use of Achilles Tendon Sonography to Distinguish Familial Hypercholesterolemia from Other Genetic Dyslipidemias. Arteriosclerosis, Thrombosis, and Vascular Biology, 25, 2203-2208. https://doi.org/10.1161/01.ATV.0000183888.48105.d1 
Submit or recommend next manuscript to SCIRP and we will provide best service for you:

Accepting pre-submission inquiries through Email, Facebook, LinkedIn, Twitter, etc. A wide selection of journals (inclusive of 9 subjects, more than 200 journals) Providing 24-hour high-quality service

User-friendly online submission system

Fair and swift peer-review system

Efficient typesetting and proofreading procedure

Display of the result of downloads and visits, as well as the number of cited articles Maximum dissemination of your research work

Submit your manuscript at: http://papersubmission.scirp.org/

Or contact ojo@scirp.org 